\title{
Treatment of Refractory Obesity with Fenfluramine
}

\author{
J. F. MUNRO,* M.B., M.R.C.P.ED. ; D. A. SEATON,* M.D., M.R.C.P.ED., M.R.C.P.GLAS.
}

L. J. P. DUNCAN,* M.B., B.SC., F.R.C.P.ED.

Brit. med. F., 1966, 2, 624-625

Fenfluramine hydrochloride (Ponderax) is a recently marketed appetite-depressant. Although it has some chemical resemblance to the amphetamines, it is not metabolized by the body to produce amphetamine and is excluded from the Drugs (Prevention of Misuse) Act, 1964 . We report the results of a 12weeks double-blind clinical trial of this drug in a group of women having refractory obesity.

\section{Materials and Methods}

The 60 women who started the trial were mostly middleaged housewives, none of whom had oedema or were known to have any cardiac disorder. All were clinically obese, overweight by at least $20 \%$ of their standard (U.S.A. MedicoActuarial Investigation, 1912), and had " refractory obesity" as previously defined (Duncan et al., 1960). Thus they had regularly attended the Diabetic and Dietetic Department during the previous year for dietetic advice and supervision, but had not lost weight appreciably in the three months before the study or taken any anorectic drug in the previous six months. The patients were matched by age, standard weight, and excess weight to form two comparable groups. By chance 25 subjects in each group completed the study, and Table I sets out their relevant data.

TABLE I.-Mean Figures and Range for the 50 Patients who Completed

\begin{tabular}{|c|c|c|c|}
\hline & & $\begin{array}{c}\text { Group A } \\
\text { (Fenfluramine) } \\
25 \text { Patients }\end{array}$ & $\begin{array}{c}\text { Group B } \\
\text { (Dummy) } \\
25 \text { Patients }\end{array}$ \\
\hline 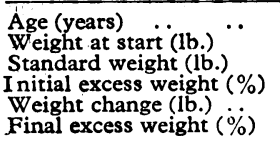 & $\begin{array}{l}. \\
\because \\
\because \\
\therefore\end{array}$ & $\begin{array}{l}49 \cdot 3(22 \text { to } 72) \\
199 \cdot 9(150 \text { to } 268) \\
138 \cdot 2(123 \text { to } 153) \\
44 \cdot 7(22 \text { to } 91) \\
-9 \cdot 3(-1 \text { to }-20) \\
38 \cdot 0(12 \text { to } 82)\end{array}$ & $\begin{array}{l}49 \cdot 6(25 \text { to } 66) \\
195.7(156 \text { to } 235) \\
139 \cdot 1(123 \text { to } 153) \\
40.8(22 \text { to } 81) \\
+0.4(+8 \text { to }-7) \\
41 \cdot 2(21 \text { to } 86)\end{array}$ \\
\hline
\end{tabular}

At the beginning of the trial all subjects were told how and why it was going to be conducted. No alteration was made to the diet they were then supposed to be taking, and they were asked to come to a special clinic every two weeks wearing as nearly as possible the same clothing. At each visit the patient was weighed, was asked if she had noted any symptoms which she attributed to the tablets, and was given a further two weeks' supply of tablets, the nature of which was not known to either her or the doctor.

Patients in one group were given tablets containing $20 \mathrm{mg}$. of fenfluramine hydrochloride, and those in the other group inert tablets identical in appearance, taste, and consistency with the active preparation. All took two tablets half to one hour before the main meal of the day and one tablet before each of two other meals, except a few patients who ate only two meals a day, who took two tablets before each of them. At the end of the study the pharmaceutical company supplying the tablets revealed which were the active and which the inert ones.

\section{Results}

Five patients in each group did not complete the trial. Of those taking fenfluramine one never took the tablets, two stopped taking them because of diarrhoea, and two became pregnant. Four taking the dummy tablets defaulted for reasons that could not be ascertained, and another stopped the tablets because she was gaining weight and considered them "useless."

Table I shows that at the end of the 12-weeks study the mean weight change of patients taking fenfluramine was $-9.3 \mathrm{lb}$. $(-4,220$ g. $)$ and of those taking the dummy $+0.4 \mathrm{lb} .(+180 \mathrm{~g}$.$) ;$ this difference is statistically highly significant $(P<0.001)$. Moreover, all those taking fenfluramine lost weight, whereas in the group taking the dummy 10 lost, 14 gained, and 1 was unchanged in weight.

The Figure shows that the mean weight of the patients taking fenfluramine continued to decrease during the 12-weeks period, although the mean weight loss in each fortnightly period was becoming less, being $-2.8,-1.6,-1.8,-1.2,-1.5$, and -0.5 lb. $(-1,270,-725,-815,-545,-680$, and -225 g. $)$ for each of the successive periods. The apparent reduction in effect of fenfluramine is less pronounced if the mean weight loss of those taking fenfluramine is compared with the mean weight change of those taking the dummy, the differences in each succeeding fortnightly period being $-1.8,-1.8,-1.9,-1.4$, -1.5 , and $-1.3 \mathrm{lb}(-815,-815,-860,-635,-680$, and -590 g.) respectively. However, because of the wide variation in weight loss between individuals in both groups it is not possible to determine statistically whether or not this represents a significant falling off in the weight-reducing effect of the drug.

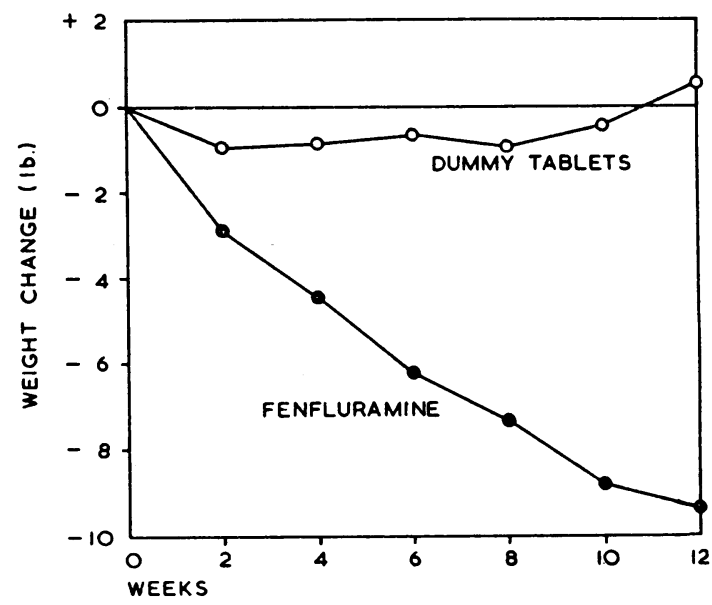

Mean loss of weight of patients taking fenfluramine compared with mean change in weight of those taking dummy tablets.

The subjective effects reported by patients and thought by them to be due to the tablets are set out in Table II. Diarrhoea was the most common, occurring in 10 patients taking fenfluramine. Two of these stopped taking the tablet because of it, one of them passing more than 20 loose motions in the day; diarrhoea recurred in both when they started taking the fenfluramine again. Five patients taking the inert tablets also said they had some diarrhoea, but in none was it severe.

* Diabetic and Dietetic Department, Royal Infirmary of Edinburgh. 
Table II.-Subjective Effects Reported During the Trial and Attributed by the Patients to the Tablet Prescribed

\begin{tabular}{|c|c|c|c|}
\hline \multicolumn{2}{|l|}{ Subjective Effect } & \multirow{2}{*}{$\begin{array}{c}\text { Fenfluramine } \\
4 \\
10 \\
0 \\
3 \\
3\end{array}$} & \multirow{2}{*}{ 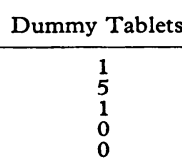 } \\
\hline $\begin{array}{llr}\text { Dry mouth } & \ldots & \ldots \\
\text { Diarrhoea } & \ldots & \ldots \\
\text { Constipation } & \ldots & \ldots \\
\text { Lightheaded } & . & \ldots \\
\text { Abdominal discomfort }\end{array}$ & $\begin{array}{l}\ldots \\
\because \\
\cdots\end{array}$ & & \\
\hline
\end{tabular}

\section{Discussion}

Earlier studies on the value of fenfluramine as an appetitedepressant were encouraging. Traherne (1965) reported a mean weight loss of $7.0 \mathrm{lb}$. $(3,175 \mathrm{~g}$.) in patients taking fenfluramine for 12 weeks, compared with a loss of $2.3 \mathrm{lb}$. (1,040 g.) in those given placebo tablets ; Duncan et al. (1965) found that patients given fenfluramine for four weeks, lost, on average, $8.9 \mathrm{lb}$. $(4,040$ g.), whereas those taking a placebo lost $4.4 \mathrm{lb}$. (1,995 g.). In both studies, however, patients were instructed in a lowcalorie diet at the start of the study, which makes it difficult to assess the effect of the drug.

The present investigation was carried out on patients with " refractory obesity." Such subjects provide a severe test for an appetite-depressant, but one which is valuable because they form a fairly standard group and are also those most in need of an effective aid to dieting. In an attempt to eliminate the influence of dietary change the patients were asked to make no deliberate alteration in their dietary habits ; that this was effective is suggested by the poor response of those taking the inert tablets.

The mean weight loss of $9.3 \mathrm{lb}$. (4,220 g.) in 12 weeks which occurred in the patients taking the fenfluramine is greater than that obtained in trials of comparable duration in similar patients having refractory obesity using phenmetrazine (Duncan et al., 1960), diethylpropion (Seaton et al., 1961), chlorphentermine (Seaton et al., 1964a), and dexamphetamine and phentermine (Seaton et al., 1964b), in which the mean weight loss varied from $2.6 \mathrm{lb}$. (1,180 g.) with diethylpropion to $6.3 \mathrm{lb}$. (2,860 g.) with dexamphetamine. Moreover, whereas all the above preparations had clearly lost their appetite-suppressant effect in the majority of patients within 12 weeks, no such tolerance to the drug was demonstrated with fenfluramine. However, a longer study than that reported here would be required to demonstrate if and when fenfluramine loses its appetitedepressant effect. Thus fenfluramine, although expensive, appears to be a more effective appetite-suppressant than the other anorectic drugs that we have so far tested.

However, a mean weight loss of only $9.3 \mathrm{lb}$. (4,220 g.) in 12 weeks is still not very substantial, though it does represent a mean reduction in food intake of about 300 calories a day from that which would have kept the patient's weight steady.

Side-effects were not particularly troublesome, although diarrhoea occurred in 10 of the 25 patients taking fenfluramine, being severe in two. Evidence of C.N.S. stimulation was not obtained in the present study, and the drug has previously been shown to have no hypertensive action (Le Douarec and Schmitt, 1964 ; Lambusier, 1965).

\section{Summary}

The appetite-depressant action of fenfluramine was evaluated against an inert tablet by a 12-weeks double-blind trial in 60 women having " refractory obesity"; 50 patients completed the trial. The mean weight change after 12 weeks was $-9.3 \mathrm{lb}$. $(-4,220$ g. $)$ in those taking fenfluramine, whereas in those given dummy tablets it was $+0.4 \mathrm{lb}$. $(+0.180 \mathrm{~g}$.).

Side-effects were not troublesome, although 2 of the 10 patients experiencing diarrhoea had to stop taking the tablets; there was no evidence of stimulation of the central nervous system.

No definite loss of effect occurred during the 12-weeks trial period, and the mean weight loss was greater than that achieved by various amphetamine derivatives in earlier trials on similar patients.

We wish to thank Selpharm Laboratories Ltd. for supplies of fenfluramine (Ponderax) and dummy tablets. We are grateful for the assistance of Miss E. M. Wilson, Chief Dietitian, and the nursing staff of the Diabetic and Dietetic Department, Royal Infirmary, Edinburgh. Dr. Donald Cameron made the statistical analysis.

\section{REFERENCES}

Duncan, E. H., Regan, N. A., Hyde, C. A., and Sweetman, B. (1965) Brit. F. clin. Pract., 19, 451.

Duncan, L. J. P., Rose, K., and Meiklejohn, A. P. (1960). Lancet, 1, 1262.

Lambusier, P. (1965). Vie méd., 46, 679.

Le Douarec, J. C., and Schmitt, H. (1964). Thérapie, 19, 831.

Seaton, D. A., Duncan, L. J. P., Rose, K., and Scott, A. M. (1961) Brit. med. F., 1, 1009.

- Rose, K., and Duncan, L. J. P. (1964a). Practitioner, 193, 698.

- L (1964b). Scot. med. f., 9, 482

Traherne, J. B. (1965). Practitioner, 195, 677.

\section{Preliminary Communications}

\section{Pilot Trial of an Antiviral Agent in Malignant Disease}

\section{Brit. med. F., 1966, 2, 625-627}

Methisazone ( $N$-methylisatin $\beta$-thiosemicarbazone, 33T57, Marboran) has been shown to be effective in vitro against pox viruses (Sheffield et al., 1960) and adenoviruses (Bauer, personal communication, 1966). In human trials it acts as a prophylactic against smallpox infection in contacts (Bauer et al., 1963) and inhibits the effects of vaccination (Landsman and Grist, 1964). As treatment for the established condition it has been reported to be successful in eczema vaccinatum (Turner et al., 1962), generalized vaccinia (Davidson and Hayhoe, 1962), and vaccinia gangrenosa (Daly and Jackson, 1962). It was unsuccessful in Marsden's (1962) case of smallpox and another case of vaccinia (Connolly et al., 1962).
Two of the successfully treated patients (Daly and Jackson, 1962 ; Davidson and Hayhoe, 1962) became ill after vaccination while taking prednisolone for a follicular lymphoma and acute leukaemia respectively. No mention is made in either report of the effect of the compound on the underlying disorder, but in the latter, from the figures given, the patient's haematological state seemed to improve in spite of reduction in steroid and cytotoxic medication. Since it seemed possible that this<smiles>CN1C(=O)/C(=N\NC(N)=S)c2ccccc21</smiles>

Fig. 1.-Molecular diagram of methisazone. 